\title{
Molecular Storytelling for Structural Biology Outreach and Education
}

\author{
D Goodsell ${ }^{1}$, S Dutta ${ }^{2}$, M Voigt $^{2}$, C Zardecki ${ }^{3}$, S Burley ${ }^{4}$ \\ ${ }^{1}$ The Scripps Research Institute, La Jolla, CA, ${ }^{2}$ RCSB Protein Data Bank, Piscataway, NJ, ${ }^{3}$ Rutgers \\ Proteomics, RCSB Protein Data Bank, Piscataway, $N J,{ }^{4} R C S B$ PDB, Rutgers University \\ goodsell@scripps.edu
}

Knowledge about the structure and function of biomolecules continues to grow exponentially, enabling us to "see" structural snapshots of biomolecular interactions and functional assemblies. At PDB-101, the educational portal of the RCSB Protein Data Bank, we have taken a storytelling approach to make this body of knowledge accessible and comprehensible to a wide community of students, educators and the general public. For 20 years, the Molecule of the Month series has utilized a traditional illustrated storytelling approach that is regularly adapted for classroom instruction. Similar visual and interactive storytelling approaches are used to present topical subjects at PDB-101, and full curricular materials for building a detailed narrative around topics of particular interest. This emphasis on storytelling led to the Video Challenge for High School students, now in its 7th year. In this workshop, I will present some of the lessons we have learned for teaching and communicating structural biology using the PDB archive of biomolecular structures. PDB-101 and the RCSB PDB are funded by the National Science Foundation (DBI-1832184), the US Department of Energy (DE-SC0019749), and the National Cancer Institute, National Institute of Allergy and Infectious Diseases, and National Institute of General Medical Sciences of the National Institutes of Health under grant R01GM133198.

Acta Cryst. (2020). A76, a9 